\title{
Everyday Confrontation of Discrimination: The Well-Being Costs and Benefits to Women over Time
}

\author{
Mindi D. Foster ${ }^{1}$ \\ ${ }^{1}$ Department of Psychology, Wilfrid Laurier University, Waterloo Ontario \\ Correspondence: Mindi D. Foster, 75 University Ave. West, Waterloo, ON, N2L3C5, Canada. Tel: \\ 1-519-884-0710. E-mail: mfoster@wlu.ca
}

$\begin{array}{lc}\text { Received: May 2, } 2013 & \text { Accepted: May 21, } 2013 \quad \text { Online Published: August 15, } 2013 \\ \text { doi:10.5539/ijps.v5n3p135 } & \text { URL: http://dx.doi.org/10.5539/ijps.v5n3p135 }\end{array}$

\begin{abstract}
Taking action against discrimination has positive consequences for well-being (e.g., Cocking \& Drury, 2004) but most of this research has focused on collective actions and has used methodologies assessing one point in time. This study therefore used a diary methodology to examine how women's everyday confrontations of discrimination would affect measures of subjective and psychological well-being, and how these relationships would change over time. In a 28-day online diary study, women indicated their daily experience of discrimination, described their response, and completed measures of well-being. Results showed that at the beginning of the study, using indirect confrontation predicted greater well-being than using angered confrontation. However, continued use of indirect and educational confrontation decreased well-being whereas continued use of angered confrontation increased well-being over time. By the end of the study, using angered confrontation predicted greater well-being than using indirect confrontation. Analyses of linguistic markers were consistent with the explicit measures of well-being. Implications for distinguishing between types of confrontations and integrating time analyses are discussed.
\end{abstract}

Keywords: confrontation, collective action, discrimination, women, well-being

\section{Introduction}

Women's experiences of discrimination are associated with depression, reduced self-esteem, subjective well-being (Branscombe, Schmitt \& Harvey, 1999; Foster, 2009a; Klonoff, Landrine \& Campbell, 2000; Moradi \& Subich, 2002) and physical disturbances like negative health behaviours, physical pain, and stress-reactive hormones (Matheson \& Anisman, 2009; Townsend, Major, Gangi \& Mendes, 2011; Zucker \& Landry, 2007). It is therefore important to identify ways to reduce the negative effects of discrimination. While group identification is a well documented means of enhancing well-being (e.g., Haslam, Jetten, Postmes \& Haslam, 2009; Branscombe et al., 1999; Jetten, Branscombe, Schmitt \& Spears, 2001; Outten, Schmitt, Garcia, \& Branscombe, 2009; Schmitt, Branscombe \& Postmes, 2003), taking action against discrimination may perform double duty, serving both the individual and group. However, research on whether action-taking affects well-being has focused on collective actions (e.g., protest marches) rather than women's everyday actions (e.g., confronting a sexist comment), and has assessed only one point in time. This study therefore used a diary methodology to examine how women's everyday confrontations of discrimination would affect subjective and psychological well-being, and how these relationships would change over time.

\subsection{Background}

There is a growing body of research suggesting collective action positively affects well-being. Greater participation in collective actions against issues such as unwanted roads and taxes (e.g., attending protests, causing work disruptions) are associated with increased collective empowerment (Cocking \& Drury, 2004; Drury, Cocking, Beal, Hanson \& Rapley, 2005; Drury \& Reicher, 1999). Experimental evidence also shows that protesting governmental or university policy by signing a petition or emailing about the issue leads to greater collective empowerment (Van Zomeren, Drury \& Van der Staaij, 2012), positive affect (Becker, Tausch \& Wagner, 2011), self-esteem and less negative affect (Foster, 2013) than not taking action. Thus, collective action against discrimination appears to benefit well-being.

What is even less understood however, are the smaller scale actions that women use in response to everyday 
discrimination. Diary research (Brinkman \& Rickard, 2009; Foster, 2009; Hyers, 2007, 2010; Swim, Hyers, Cohen \& Ferguson, 2001; Swim, Hyers, Cohen, Fitzgerald \& Bylsma, 2003) has shown that women's daily experiences of both sexism and racism include negative comments/stereotyping by family and romantic partners, being excluded, and sexual objectification (Brinkman \& Rickard, 2009; Foster, 2009; Hyers, 2007, 2010; Swim, et al., 2001; Swim, et al., 2003). Although such experiences may at first glance, seem more benign than institutional threats, these studies also reveal the chronic and repetitive nature of everyday discrimination: on average it occurs one to three times per week (Hyers, 2007; Foster, 2009; Swim et al., 2001) and as often as one (Swim et al., 2001, Study 3) to two times per day (Brinkman \& Rickard, 2009). Thus, akin to the negative effects of daily hassles (Kanner, Coyne, Schaefer \& Lazarus, 1981), the ubiquitous nature of everyday discrimination suggests that everyday confrontations may have negative consequences for women's well-being.

There is some non-diary work on suggesting that confrontation may indeed decrease well-being. First, research on the social costs of confronting shows that confronters are perceived as complainers, are less well-liked and experience retaliation (e.g., Garcia, Reser, Amo, Redersdorff, \& Branscombe, 2005; Kaiser \& Miller, 2001, 2003). Thus, if confronting discrimination causes additional difficulties for the victim, then a decrease in well-being might also be expected. Second, correlational studies have shown that direct confrontations (e.g., "I directly challenge the person who offended me"; Wei, Alvarez, Ku, Russell \& Bonnett, 2010) or reporting of sexual harassment (Bergman, Lanhout, Palmieri, Cortina \& Fizgerald, 2002) are associated with decreased life satisfaction and increased distress, respectively.

While this data suggests confrontations within an interpersonal context may reduce well-being, there are nevertheless gaps in this research. First, the social costs of confrontation literature provides only indirect support for the notion that confrontation decreases well-being. Second, it is unclear whether the correlational studies (Bergman et al., 2002; Wei et al., 2010) were in fact examining confrontations that women used on an everyday basis. For example, the instructions given to participants in Wei et al.'s (2010) study do not clarify whether confrontations were recalled from a behavioral repertoire that women actually used or whether they study was measuring anticipated confrontations in response to hypothetical discrimination (i.e., what would they would use). Finally, the few diary studies that have documented everyday confrontations have not examined well-being (Hyers, 2007, 2010; Swim et al., 2003). Thus, one goal of this study was to use a daily diary methodology to assess women's everyday confrontations of discrimination, and their effects on well-being.

A second goal was to assess whether these relationships would vary with time. The process approach to coping (Lazarus, 1993; Lazarus \& Folkman, 1984) argues that because a stressor changes over time, so too do coping responses. The changing nature of these relationships means that a strategy beneficial to well-being at one point in the process may not be as helpful at a different point. For this reason, Lazarus and Folkman (1984) argue that stress responses are best assessed over time so that changing relationships can be captured. However, most research on confrontation and well-being has been examined only in the context of experimental or correlational paradigms, both conducted at one point in time (e.g., Becker et al., 2011; Bergman et al., 2002; Cocking \& Drury, 2004; Foster, 2013; Wei et al., 2010; van Zomeren et al., 2012).

Initial attempts to investigate changes over time have been examined in a 28-day online diary examined the relationships between everyday discrimination and coping styles (Foster, 2009b, Foster, 2009b). Results showed that those who viewed discrimination as pervasive were less likely to use active coping (problem-solving) than behavioural disengagement (giving up) strategies at the beginning of the study. But, behavioural disengagement declined such that by month's end, participants were more likely to use active coping than behavioural disengagement. Thus, consistent with the process approach to coping (Lazarus \& Folkman, 1984), this study showed that women's coping responses to discrimination changed over time, but how they affect well-being was not examined.

A concurrent study, (Foster, 2009a) examined how responses to a lab simulation of discrimination predicted women's immediate well-being, and well-being one year later. Women completed a task and told their success or failure would be judged by a male student-experimenter who had been previously successful; he told women their scores were unacceptable whereas the men's scores were successful. Women then completed measures of their behavioural intentions (i.e., confronting the experimenter who failed them or doing nothing) and well-being. One year later, additional measures of well-being were completed. Initially, among those who viewed discrimination as pervasive, increased endorsement of confrontations were associated with lower well-being. However, initial endorsement of confrontation was unrelated to well-being one year later. Thus, whether confrontation can affect well-being over time is still unclear. Because confrontations were operationally defined within the context of the experiment (e.g., confronting the experimenter), their limited generalizability may mean they were not salient enough to be relevant predictors of well-being one year later. Moreover, these 
confrontations were endorsements rather than actual confrontations. Thus, the present study sought to extend this research by using the diary methodology from Foster (2009b), but to examine how women's actual everyday confrontations may affect well-being over time.

\subsection{Hypotheses}

Because research to date has not assessed how everyday confrontation may affect well-being over time, expectations about changes over time were derived from Pennebaker's work on emotional expression and well-being (e.g., Pennebaker \& Chung, 2007). In particular, Pennebaker and others have shown that by expressing emotions, well-being improves over time (e.g., Campbell \& Pennebaker, 2003; Frisina, Borod \& Lepore, 2004; King \& Miner, 2000). As such, although confrontations that involve direct communication to the perpetrator may be difficult initially and may lower well-being at one point in time (e.g., Bergman et al., 2002; Foster, 2009a; Wei et al., 2010) the benefits of direct confrontations may be seen after some time to the extent that such confrontations involve being able to express oneself. As such,

Hypothesis 1 states: continued use of direct confrontations will be associated with increasing well-being over time.

In contrast, Pennebaker (e.g., Pennebaker \& Chung, 2007) suggests the act of trying to keep in, or inhibit one's emotions takes sustained effort which can ultimately reduce people's mental and physical resources. Consistent with this, Foster (2009a) found greater endorsement of emotional containment after experiencing gender discrimination was related to lower well-being initially as well as one year later. Thus, indirect confrontations that involve inhibition of straightforward communication (e.g., nonverbal behaviors such as eye-rolling) may not be beneficial

Hypothesis 2 therefore states: continued use of indirect confrontations will be associated with decreasing well-being over time.

\section{Method}

\subsection{Participants}

Given diary research involves a resource burden for researchers and workload burden for participants, a targeted sample was desired; participants were pre-selected if they perceived discrimination to be pervasive (i.e., occurring frequently across many contexts; Branscombe et al., 1999). This group is most vulnerable to negative health outcomes (Branscombe et al., 1999; Foster \& Dion, 2003; Foster, Jackson, Hartmann \& Woulfe, 2004; Schmitt, Branscombe, Kobrynowicz \& Owen, 2002; Stroebe, Barreto \& Ellemers, 2010), and therefore most in need of positive interventions. Moreover, because perceived pervasiveness is positively related to taking action (Foster, 2000, 2001, 2009a) the variability in confrontations could be maximized. Female participants were therefore selected from an online mass testing session for the psychology department's participant pool.

Those who qualified $(N=49, M$ age $=19.5, S D=2.2)$ were given course credit for attending an orientation session and $\$ 75$ upon completing the diary. Reported ethnicity was $53.4 \%$ White Canadian, $20.4 \%$, Eastern Asian (Chinese, Japanese, Korean), 8.7\% South Asian (e.g., East Indian, Pakistani), 5.8\% Black, 3.9\% Hispanic, 2.9\% Arabic, 2.9\% Filipino, 1\% South East Asian, 1\% First Nations. Reported majors were 40.6\% Arts (e.g., English, Sociology), 29.1\% Business/Economics, 18.3\% Psychology, $12 \%$ Science (Biology, Kinesiology, Math). All participants completed the study.

\subsection{Procedure}

Participants who qualified were brought into the lab for an orientation, that involved (1) completing a set of pre-measures, (2) an introduction to the topic of interest and (3) training on how to log in and complete the online diary.

First, given the relationship between negative affectivity and well-being (e.g., Diener, 1984; McCrae \& Costa, 1987), neuroticism and depression were included as possible covariates. Then, to introduce participants to the topic of interest they were given an explicit definition of discrimination (see Foster, 2009b). This was done for two reasons. First, given the robustness of the personal/group discrimination discrepancy (e.g., Crosby, 1984; Taylor, Wright, Moghaddam \& Lalonde, 1990) whereby disadvantaged group members minimize personal discrimination, it was expected participants would struggle with defining discrimination. Second, because the norm among disadvantaged group members is acceptance of discrimination rather than action (e.g., Wright, 2001) and further, that subtle sexism reduces collective action-taking (Ellemers \& Barreto, 2009), an explicit definition of discrimination was necessary to maximize the variability of confrontations reported.

Participants were then told that the focus of the research was not on the incident itself, but how they responded to 
it, and asked to describe the range of responses they took to respond.

Finally, participants training on how to log in and complete the online diary.

\subsection{Measures}

\subsubsection{Perceived Pervasiveness}

During mass-testing, participants completed the Perceived Ethnic Discrimination Questionnaire (Contrada, Ashmore, Gary, Coups, Egeth, \& Sewell, et al., 2001), which assesses perceptions of discrimination across different contexts (e.g., home, work, school) and in different forms (e.g., verbal rejection, avoidance, aggression). Because the questions originally focused on ethnicity, items were re-worded where appropriate to include reference to both gender and ethnicity, or discrimination generally so as not to limit which type of discrimination was salient to participants (e.g., " How often have you been subjected to discriminatory name-calling (e.g., "N-----",Bitch")"). Participants rated 22 items (never (1) to very often (7)). The mean was used as the overall score $($ Cronbach, alpha $=.88)$. Median splits were conducted to select those perceiving high pervasiveness $(M=$ 2.6, $S D=.69, M d n=2.6)$.

\subsubsection{Pre-Measures}

Participants rated (strongly disagree (-3) to strongly agree (3)) the eight-item Neuroticism sub-scale from the NEO Five-Factor Inventory-Short form (John \& Srivastava, 1999; e.g., "I see myself as someone who worries a lot"). The mean was used as the overall score (Cronbach alpha $=.77$ ). Depression was measured using the Center for Epidemiological Studies-Depression scale (Radloff, 1977). Participants rated 20 statements on how often (rarely or none of the time/less than one day (0) to most or all of the time/ 5-7 days (3)) they experienced 20 symptoms (e.g., "I felt lonely"). The mean was used as the overall score (Cronbach alpha $=.90)$.

\subsubsection{Daily Diary Entries}

Discrimination. Upon logging in participants completed checklists describing their experience of discrimination. These checklists were derived from a previous study (Foster, 2009b), which presented the same definition of discrimination, and asked women to describe their daily experiences of discrimination. Those experiences were coded, providing the basis for the presently-used checklists. Participants indicated whether the discrimination was "sexism", "racism", "not sure what type of discrimination", or "no discrimination was experienced today." If no discrimination was experienced the session was ended to reduce possible diffusion effects common to repeated measures designs (Cook \& Campbell, 1979). When discrimination was indicated, participants further described it by checking either "negative comments/stereotypes", "harassment (verbal or physical)", "exclusion (being prevented from doing something due to gender/ethnicity)", or "being ignored or receiving poor service". Location of the discrimination was indicated by checking either "work", "home", "academic (i.e., class, group work)", "on campus but not academic (e.g., pubs, extra curricular)" or "off campus". Finally, participants indicated the perceived severity of the discrimination (not at all severe (1) to extremely severe (7)), as a potential covariate.

Responses to discrimination. Participants then saw a text box with the same instructions given during orientation to describe their response to the discrimination.

Subjective well-being. Consistent with Diener (1984), mood and life satisfaction were assessed. Given the workload burden for participants, daily questionnaires are kept short (Bolger, Davis \& Rafaeli, 2003; DeLongis, Hemphill, \& Lehman, 1992). Therefore, two sub-scales from the Positive and Negative Affect Scale-Expanded form were used (PANAS-X; Watson \& Clark, 1994), namely self-assurance (proud, strong, confident, bold, daring, fearless) and fear (afraid, scared, frightened, nervous, jittery, shaky). The other sub-scales were not included as they either appeared too irrelevant (e.g., attentive) or, extreme (jovial) in response to discrimination, or, included specific descriptors that the young participants would not likely use and as such, not ecologically valid (e.g., "scornful"). Moreover, the sub-scales chosen have also been noted as typical moods reported when experiencing discrimination (Hyers, 2007; Swim, et al., (2003). Participants rated each adjective in terms of how they felt "today" (very slightly or not at all (1) to extremely (5)). The means across each set of adjectives were used as the overall self-assurance and fear scores. Also, a one item measure of happiness ("How happy do you feel today?") was included.

Life satisfaction was measured using a five-item scale (Revicki, Turner, Brown, \& Martindale, 1992). Across five domains (life as a whole, physical health, work life, home life, social life), participants indicated how satisfied they felt about their life today (very slightly or not at all (1) to extremely (5). The mean was used as the overall sore. 
Psychological well-being. To keep daily reports brief, three sub-scales from the short form of Ryff's Psychological Well-being scale (Ryff \& Keyes, 1995) were used: autonomy (e.g., "I have confidence in my opinions even if they are contrary to the general consensus"), positive relations (e.g., "Maintaining close relationships has been difficult and frustrating for me"), and mastery (e.g., "I am quite good at managing the many responsibilities of my daily life"). Again, the other sub-scales were not included as they included items that did not appear ecologically valid in that student populations may not have the life experience to answer them accurately or would find them irrelevant (e.g., "For me, life has been a continuous process of learning, changing and growing" in the Positive Growth subscale). Using a scale ranging from strongly disagree (1) to strongly agree (5), participants indicated how much they agreed/disagreed that each statement described them. The mean across each set of three items was used for the scores; higher scores represented higher autonomy, positive relations, and mastery.

In longitudinal data, reliability estimates represent how reliability across the 28 days. The estimates, which were computed using a formula (3.21) provided by Snijders \& Bosker (1999), ranged from .97 to .99 .

\subsubsection{Linguistic Markers}

The words individuals choose to convey their meanings provide information about social and psychological process as well as health and well-being (e.g., Pennebaker \& Chung, 2007; Tausczik \& Pennebaker, 2010). As such, linguistic markers of various processes were explored as less obtrusive measures. Participant's daily entries were analyzed using Linguistic Inquiry and Word Count (LIWC; Pennebaker, Chung, Ireland, Gonzales \& Booth, 2007), a text analysis program calculating the percentage of total number of words for each word category.

The categories of interest were chosen based on past research that has linked them to well-being outcomes. For example, those who write about resolved events use more past tense words (Pasuputhi, 2007); more past tense and fewer present tense words are linked with decreased grief and trauma (Boals \& Klein, 2005; Pillemer, Desrochers \& Ebanks, 1998). First-person singular pronouns (e.g., I, me) are related to depression (e.g., Gortner $\&$ Pennebaker, 2004; Sloan, 2005). More positive than negative emotion words as well as more meaning-making words (cause and insight) indicate recovery from emotional trauma (i.e., they have cognitively processed the event and are moving toward feeling more positive than negative) and are linked to health and well-being (e.g., Pennebaker, Mehl, \& Niederhoffer 2003). Social words (e.g., relationship, share) indicate social connectedness (Burke \& Dollinger, 2005) and is related to longevity (Pressman \& Cohen, 2007). Finally, given the relationship between traumatic memory and somatic activation (Foa \& Kozak, 1986), use of sensory or 'feel' words (feels, touch) has been linked to greater focus on a negative experience (e.g., Guastella \& Dadds, 2006; Hellawell \& Brewin, 2004).

Categories related to power dynamics were also explored: certainty words (always, never) are used by those in power positions (Magee, Milliken \& Lurie, 2010), assent words (agree, OK) aid in negotiations (Huffaker, Swaab \& Diermeier, 2011) and use of auxiliary verbs (e.g., "a mistake was made but I don't blame anyone") are, by definition use of a passive voice.

\section{Results}

\subsection{Descriptive Statistics}

Out of a possible 1372 ( 28 days $\mathrm{x} \mathrm{N}=49$ ) entries, participants completed 1126 entries ( $82 \%$ participation rate), logging in on average 22.9 days out of $28(S D=3.5$, Minimum number of days $=11$, Maximum $=28)$. Of those days, $41.5 \%$ of the experiences were reported as sexism, $23.7 \%$ were reported as racism, $12.9 \%$ were reported as "not sure what type of discrimination" and $21.9 \%$ were reported as no discrimination. The majority of discrimination was experienced as negative comments/stereotypes $(62.7 \%)$, followed by being ignored (15.1\%), exclusion (12\%) and harassment (10.2\%). The location of these incidences were reported as $34.5 \%$ off campus, $23.3 \%$ on campus but not in an academic context, $22.6 \%$ at home, $13.9 \%$ in an academic context and $5.7 \%$ at work.

Means, standard deviations and intercorrelations (aggregated across time for the daily measures) for all variables appear in Table 1. 
Table 1. Means, standard deviations, inter-correlations (collapsed across time)

\begin{tabular}{|c|c|c|c|c|c|c|c|c|c|c|c|c|}
\hline & Mean & SD & 1 & 2 & 3 & 4 & 5 & 6 & 7 & 8 & 9 & 10 \\
\hline 1. Neurotic & -.08 & .74 & - & & & & & & & & & \\
\hline 2. Depression & .74 & .32 & $.37 * *$ & - & & & & & & & & \\
\hline 3. Common fate & 1.00 & .69 & .10 & -.09 & - & & & & & & & \\
\hline 4. Severity & 3.18 & .20 & .07 & -.13 & .02 & - & & & & & & \\
\hline 5. Self-assurance & 2.65 & .11 & $-.33^{*}$ & $-.28 *$ & .13 & .10 & - & & & & & \\
\hline 6. Fear & 1.67 & .11 & .20 & .20 & -.22 & .15 & .22 & - & & & & \\
\hline 7. Нарpy & 2.85 & .13 & $-.35^{*}$ & $-.35 * *$ & .04 & .20 & $.75^{* *}$ & .11 & - & & & \\
\hline 8. Life satisfaction & 3.54 & .10 & -.25 & $-.43 * *$ & .09 & -.08 & $.53^{* *}$ & -.12 & $.50 * *$ & - & & \\
\hline 9. Autonomy & 3.26 & .12 & $-.45 * *$ & -.25 & .01 & .15 & .20 & -.16 & .16 & .22 & - & \\
\hline 10. Positive relations & 2.94 & .07 & -.19 & $-.32 *$ & -.01 & .05 & .17 & $-.30^{*}$ & .17 & $.29 *$ & $.26^{\wedge}$ & - \\
\hline 11. Mastery & 3.39 & .11 & $-.29^{*}$ & $-.48 * *$ & .15 & -.01 & $.39 * *$ & $-.47 * *$ & $.34 *$ & $.61 * *$ & $.50 * *$ & $.81^{* *}$ \\
\hline
\end{tabular}

Note. ${ }^{*} \mathrm{p}<.05,{ }^{* *} \mathrm{p}<.01, \wedge \mathrm{p}<.10$. Scale endpoints were -3 to +3 for Neurotic, Common Fate; $0-3$ for Depression;

1-7 for Severity; 1-5 for the remaining scales.

\subsection{Coding Strategy}

Grounded-theory techniques were used, whereby coders attempt to ignore pre-conceived notions and instead let categories emerge from the data (e.g., Corbin \& Strauss, 2008; Cresswell, 2006). A research assistant (who had not been informed of hypotheses) was therefore explicitly asked to remain open-minded when reading through the paragraphs. Paragraphs were first read and summarized using a data-based phrase reflecting the important properties of the behaviour, as a means of avoiding pre-conceptions of participants' meanings (Corbin \& Strauss, 2008). For example, "So I said that to the boys to shut them up" was summarized as "shut them up." Category codes were then generated by grouping phrases into conceptually similar categories. For example, phrases such as "made rude comments in response" and "told off perpetrator" were grouped into "angered confrontation", as they involved confrontation with anger. Once the final codes had been established, two new research assistants read through the paragraphs to assign each a code. If participants described two behaviours, coders were instructed to use just one category code, namely the initial behaviour.

\subsection{Final Coding Schema}

Consistent with past research (e.g., Foster, 2009a; Wright, 2001), inaction was the most common response (58.9\%). Participants' descriptions were placed into this category if they described anything non-behavioural, i.e., if they merely described their experience versus a response, or, if they only described responding with a feeling (e.g., "I felt upset") or thought (e.g., "I haven't stopped thinking about it") $)^{1}$.

The remaining responses $(41.1 \%)$ were coded as behavioral confrontations because descriptions involved doing something i.e., any observable behaviour in response to the incident. These were further broken down into three categories. In particular, $46.4 \%$ of these were classified as "angered confrontation" whereby participants expressed their anger as well as beliefs about the unfairness:

This made me very angry and I immediately got into an argument with him. telling him that he had no right to say that. and that the girls in the group are definitely just as smart, if not smarter than the guys and that what we had to say is just as valid as what he would have said. I also told him that he was so ignorant and that karma will come around to him too. [Participant 3]

$22.6 \%$ of the confrontations were classified as "educational confrontation" whereby participants tried to educate the perpetrator about their behaviour but, unlike in the angered confrontation category, reported doing so calmly and politely: "I answered the question being asked with respect, and a smile. I offered a one sentence response, in a very gentle and caring manner - to educate the man." [Participant 23].

The remainder of confrontations (11.1\%) were categorized as "indirect confrontations", given participants performed an observable behaviour, but did so with indirect communication strategies. Nonverbal behaviours 
such as leaving the situation with an indirect display of discontent (e.g., "I got so upset I stormed out of the room" [Participant 8]), or body language (e.g., "I just rolled my eyes at him" [Participant 48]) are considered indirect because they are not straightforward communication tactics (LaFrance \& Harris, 2004). Sarcastic humor was also included as it softens the effect of the discontent and does not directly express the reason for discontent (LaFrance \& Harris, 2004): "My mom was making stereotypical remarks about where my boyfriend's family was from. I acted by making fun of her parent's race as a joke because I wanted to show her what she was doing" [Participant 2].

Interrater reliability for these codes was good (Cohen's Kappa $=.89, \mathrm{p}=.0001)$. Although past works differs in how these actions are labeled into higher level categories (e.g., both verbal and nonverbal confrontations have been grouped as 'assertive confrontations', Hyers, 2007; Shelton, Richeson, Salvatore \& Hill, 2006), the specific confrontation types (anger, education and indirect) have been documented in past work (e.g., Hyers, 2007, 2010; Swim et al., 2001).

\subsection{Main Analyses}

As it is necessary to account for the non-independence issues inherent in daily diary data, model building and hypothesis testing procedures for multi-level modeling (MLM; e.g., Singer \& Willet, 2003) were used. In particular, each model was compared to subsequent ones for better fit i.e., (unconditional/null; growth (effect of time); main effects (time, confrontation ${ }^{2}$; interaction (time x confrontation)). The main effect of confrontation was separated into daily confrontation (i.e., which confrontation was used on a particular day) and typical confrontation (i.e., which confrontation each individual used on average). Typical confrontation ${ }^{3}$ was included only as a means of separating the within and between-person variance. This is necessary to do when only time-varying predictors are used; otherwise the effect of time-varying behavior on time-varying well-being would be confounded by the fact that individuals differ in their average, or most typical, behavior. Including typical confrontation is therefore only a means of partialling variance, allowing for more pure estimates of the effects.

Goodness of fit was tested by examining the differences in the deviance statistic; a significant (using the chi square distribution) decrease in the deviance statistic indicates better fit (Singer \& Willet, 2003).

To address difficulty in establishing causal relationships in daily process data (e.g., Bolger et al., 2003; Singer \& Willet, 2003) a lagged predictor variable for confrontations was computed; models testing well-being examined whether confrontations on any given day predict tomorrow's well-being.

Covariates were used if they were significant predictors of the well-being variables (e.g., Snijders \& Bosker, 1999 ) and included in the appropriate models. Notably, the main effect of time on severity was not significant, $B$ $=-.002, p=.88$, indicating the methodology itself (i.e., attending to discrimination each day) did not appear to increase sensitivity to discrimination. In addition, there was no effect of severity on confrontations.

Potential moderators of these models were also tested (age, ethnicity), however none of their main effects or interactions were significant.

Table 2 shows the unstandardized estimates for well-being models.

Table 2. Unstandardized estimates for interaction models

\begin{tabular}{lllll}
\hline & Self- Assurance & Fear & Happy & Life Satisfaction \\
\hline & $\mathrm{b}(\mathrm{SE})$ & $\mathrm{b}(\mathrm{SE})$ & $\mathrm{b}(\mathrm{SE})$ & $\mathrm{b}(\mathrm{SE})$ \\
$\begin{array}{l}\text { Covariates } \\
\text { Neuroticism }\end{array}$ & $-.38^{* *}(.12)$ & -- & $-.44^{* *}(.14)$ & -- \\
$\begin{array}{l}\text { Depression } \\
\text { Intercepts }\end{array}$ & -- & -- & -- & $-.79^{* *}(.28)$ \\
Angered confrontation & $2.43^{* *}(.17)$ & $1.35^{* *}(.22)$ & $2.74^{* *}(.20)$ & $3.31^{* *}(.14)$ \\
$\begin{array}{l}\text { Educational confrontation } \\
\text { Indirect action }\end{array}$ & $2.49^{* *}(.22)$ & $1.62^{* *}(.24)$ & $2.83^{* *}(.28)$ & $3.43^{* *}(.19)$ \\
$\begin{array}{l}\text { Slopes (Time } \\
\text { Action) }\end{array}$ & $2.85^{* *}(.19)$ & $1.69^{* *}(.25)$ & $3.45^{* *}(.27)$ & $3.69^{* *}(.25)$ \\
& & & & \\
\hline
\end{tabular}




\begin{tabular}{lllll}
\hline Angered confrontation & $.02^{*}(.01)$ & $.00(.01)$ & $.01(.01)$ & $.02^{* *}(.01)$ \\
Educational confrontation & $.01(.01)$ & $.00(.01)$ & $-.01(.02)$ & $.02(.01)$ \\
Indirect action & $-.02(.01)$ & $-.01(.03)$ & $-.04^{*}(.02)$ & $.02^{\wedge}(.01)$ \\
$\chi 2(4)$ & $9.53^{*}$ & 5.30 & $18.92^{* *}$ & $15.33^{* *}$ \\
\hline \multicolumn{1}{l}{ Autonomy } & Positive Relations & Mastery & \\
Neuroticism & & & & \\
Depression & $-.32^{* *}(.13)$ & -- & -- & \\
Intercepts & -- & $-.31^{* *}(.17)$ & & \\
Angered confrontation & $3.21^{* *}(.13)$ & $3.03^{* *}(.24)$ & $3.37^{* *}(.28)$ & \\
Educational confrontation & $3.20^{* *}(.14)$ & $3.21^{* *}(.21)$ & $3.50^{* *}(.29)$ & \\
Indirect action & $3.25^{* *}(.14)$ & $3.30^{* *}(.20)$ & $3.65^{* *}(.27)$ & \\
Slopes (Time & $X$ & & & \\
Action) & & & $.02(.01)$ & \\
Angered confrontation & $.01(.01)$ & $.01(.01)$ & $-.03^{*}(.01)$ & \\
Educational confrontation & $-.01(.01)$ & $-.03^{* *}(.01)$ & $-.05^{* *}(.01)$ & \\
Indirect action & $-.01(.01)$ & $-.03^{* *}(.01)$ & $16.02^{* *}$ & \\
$\chi 2$ (4) & 7.91 & $17.32^{* *}$ & \\
\hline
\end{tabular}

Note. Intercepts refer to the score of each variable for an individual using that confrontation on day 1 of the study. For Mastery, Positive relations, the intercepts also refer to those typically using that confrontation $* p<.05,{ }^{* *} p$ $<.01, \wedge p<.10$

\subsection{Subjective Well-Being}

\subsubsection{Self-Assurance}

Controlling for neuroticism, the significant intercept, $F(1,37.24)=386.32, p=.001$ indicated there were differences in initial self-assurance scores across the confrontations. Simple effects analysis showed that initially, using indirect confrontation predicted more self-assurance than using angered confrontation, $B=-.42, p=.03$. There were no other initial differences across the responses. The main effects of time, $F(1,17.00)=.31, p=.58$ and confrontation, $F(2,136.71)=2.19, p=.12$ were not significant. However, there was a significant interaction between time and confrontation, $F(2,120.12)=3.43, p=.03$, such that using angered confrontation predicted increasing self-assurance over time (See Figure 1). In contrast, there were no significant changes as a function of educational confrontation or indirect confrontation. By the end of the month, using angered confrontation predicted more self-assurance than using indirect action, $B=.54, p=.02$. 


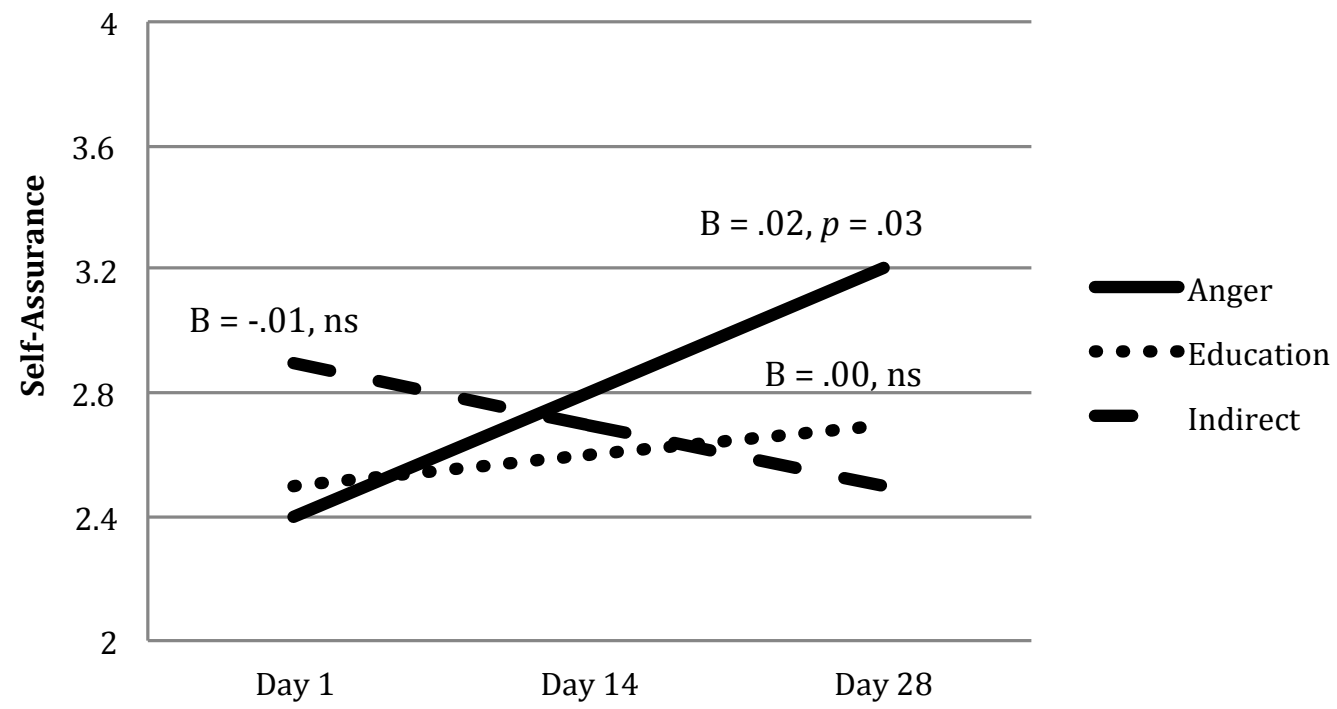

Figure 1. Self-assurance scores over time for each confrontation type

Fear. There were no significant effects on fear.

\subsubsection{Happiness}

Controlling for neuroticism, the significant intercept $F(1,21.08)=75.57, p=.001$ indicated there were differences in initial happiness scores across the confrontations. Simple effects showed that initially, using indirect confrontation predicted more happiness than using angered confrontation, $B=-.72, p=.01$ and marginally more happiness than using educational confrontation, $B=-.62, p=.06$. There were no other initial differences across the responses. The main effects of time, $F(1,25.95 .17)=.42, p=.52$ and confrontation, $F(2$, $155.44)=1.78, p=.17$ were not significant. However, there was a significant interaction between time and confrontation, $F(2,181.29)=3.32, p=.03$, such that using indirect confrontation predicted decreasing happiness over time (See Figure 2). There were no significant changes as a function of angered or educational confrontation. By the end of the month, using indirect confrontation predicted less happiness than using angered confrontation, $B=.54, \mathrm{p}=.02$. There were no other significant differences by month's end.

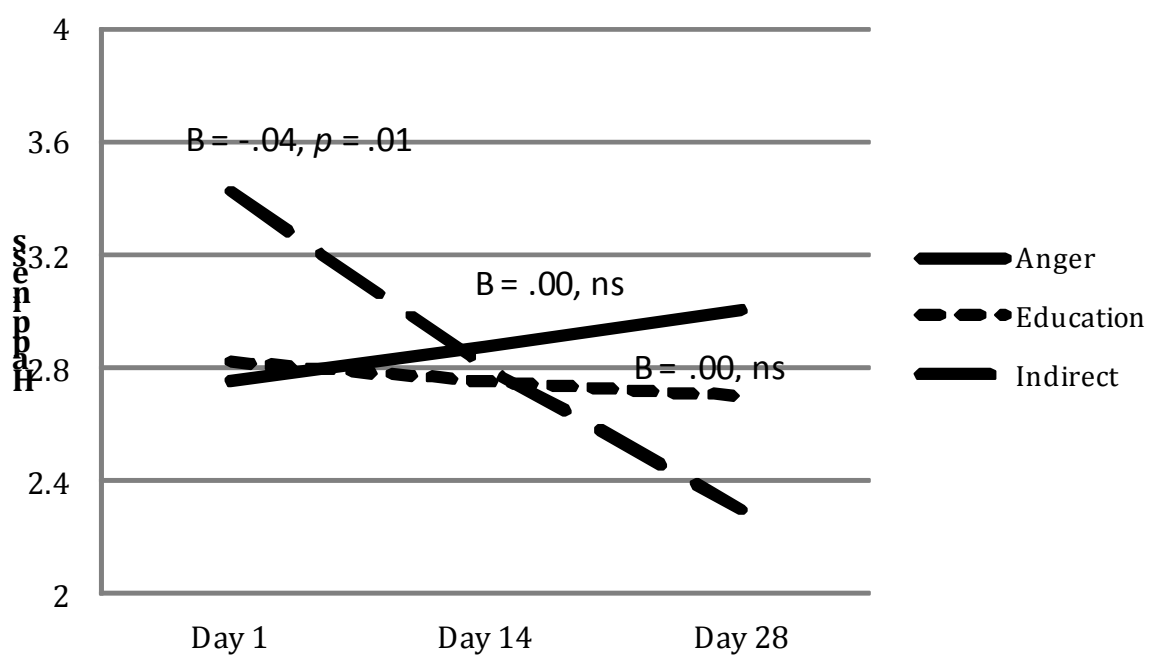

Figure 2. Happiness scores over time for each confrontation type 


\subsubsection{Life Satisfaction}

Controlling for depression, the significant intercept, $F(1,37.54)=325.08, p=.001$ indicated there were differences in initial life satisfaction scores across the confrontations, such that initially, using indirect confrontation predicted more life satisfaction than using angered confrontation, $B=-.37, p=.02$. There were no other initial differences. The main effect of time was not significant, $F(1,34.54)=.50, p=.48$. The significant main effect of confrontation, $F(2,159.39)=3.19, p=.04$ was qualified by a significant interaction between time and confrontation, $F(2,161.04)=5.55, p=.01$ such that using angered confrontation predicted increasing life satisfaction and using indirect confrontation predicted marginally decreasing life satisfaction over time (See Figure 3). The slope for educational confrontation was not significant. By month's end, using indirect confrontation predicted less life satisfaction than using angered confrontation, $B=.60, p=.002$. There were no other significant differences by month's end.

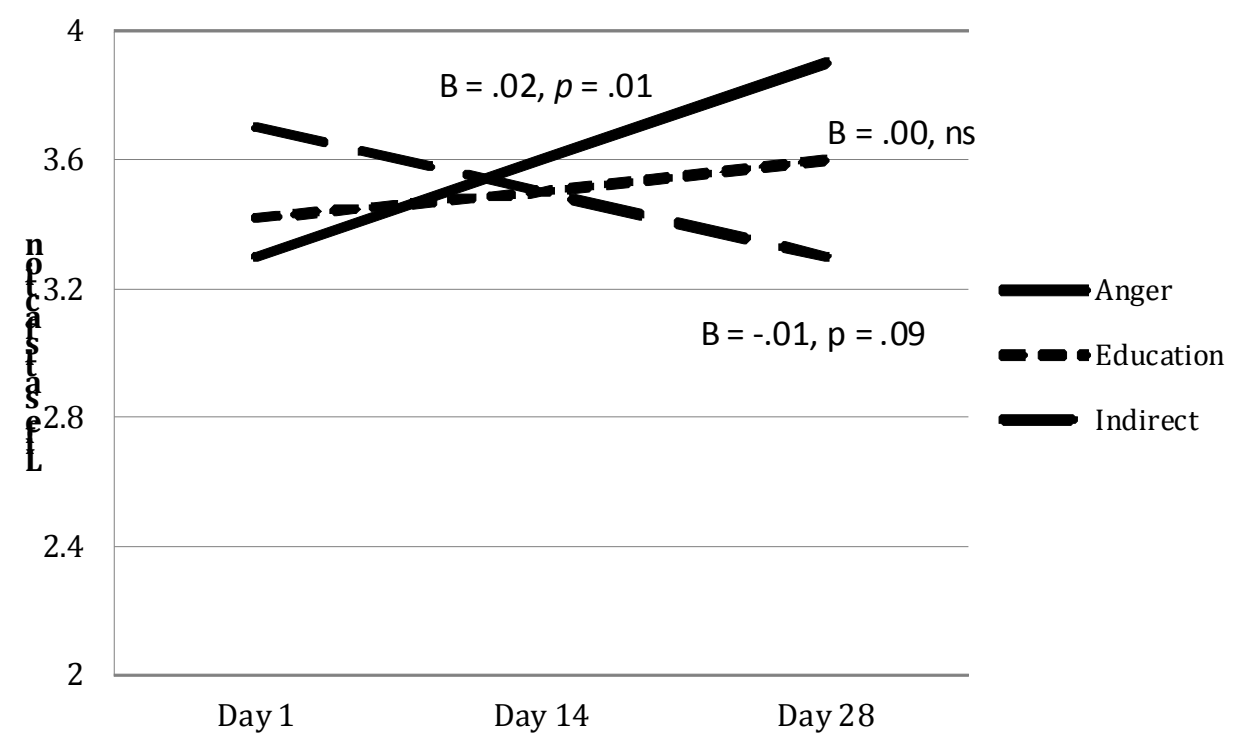

Figure 3. Life satisfaction scores over time for each confrontation type

\subsection{Psychological Well-Being}

\subsubsection{Autonomy}

There were no significant effects on autonomy.

\subsubsection{Mastery}

Controlling for depression, the significant intercept, $F(1,44.06)=314.21, p=.001$ indicated there were differences in initial mastery scores across the confrontations such that initially, using indirect confrontation predicted greater mastery than using angered confrontation, $B=-.28, p=.03$. There were no other initial differences across the responses. The significant main effects of time, $F(1,182.22)=6.51, p=.01$, and participant's typical confrontation type, $F(2,37.92)=10.98, p=.001$ were qualified by an interaction between time and daily confrontation, $F(2,182.43)=4.67, p=.01$, such that using indirect and educational confrontation predicted decreasing mastery over time (See Figure 4). The slope for angered confrontation was not significant. By month's end, using indirect confrontation predicted lower mastery than using angered confrontation, $B=.48$, $p=.002$, and marginally lower mastery than using educational confrontation, $B=.34, p=.06$. There were no other significant differences by month's end. 


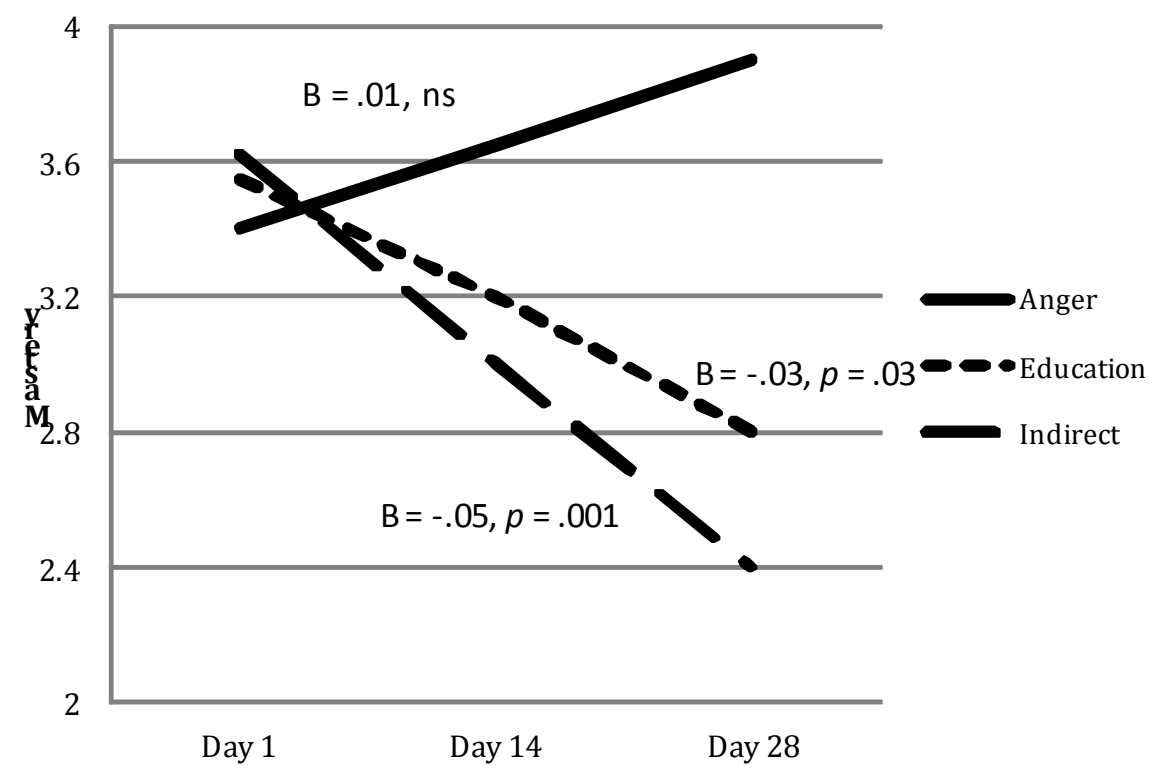

Figure 4. Mastery scores over time for each confrontation type

\subsubsection{Positive Relations}

Controlling for depression, the significant intercept, $F(1,45.65)=387.83, p=.001$ indicated there were differences in initial positive relations scores across the confrontations such that using indirect confrontation predicted marginally better positive relations than using angered confrontation, $B=-.22, p=.07$. There were no other initial differences across the responses. The significant main effects of time, $F(1,186.18)=4.26, p=.04$ and typical confrontation use, $F(2,36.10)=9.29, p=.001$ were qualified by an interaction between time and daily confrontation, $F(2,184.92)=3.12, p=.05$, such that using indirect and educational confrontation predicted decreasing positive relations (see Figure 5). The slope for angered confrontation was not significant. By month's end, using indirect confrontation predicted worse positive relations than using angered confrontation, $B=.35, p<.01$. There were no other significant differences by month's end.

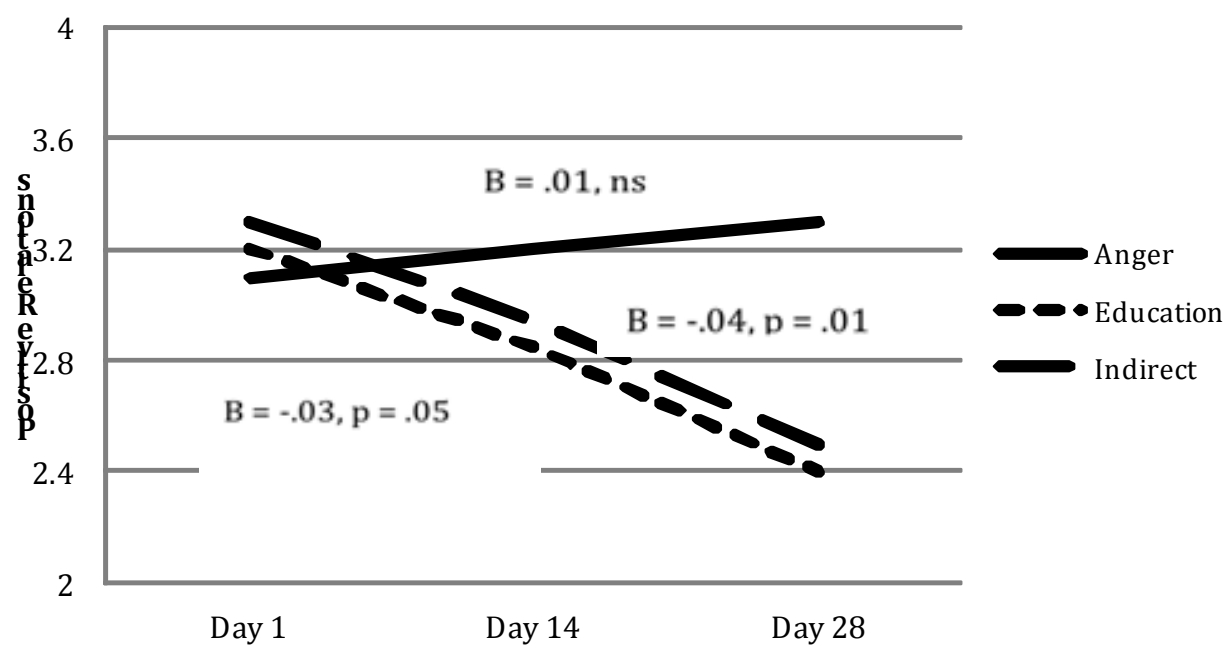

Figure 5. Positive relations scores over time for each confrontation type 


\subsubsection{Linguistic Markers}

The linguistic markers were explored also using MLM, however, because the lagged data was significantly reduced, these analyses did not converge. As such, the models assessed how confrontations on one day affect language use the same day. The same model building procedures were used, but interaction models did not fit the linguistic data, suggesting there was no systematic change in word use over time (i.e., word use did not increase or decrease in one direction over time). Instead, the main effects models were the best fit of the data, indicating the confrontations predicted both daily changes and typical word use (see Table 3).

Table 3. Unstandardized estimates for word usage models

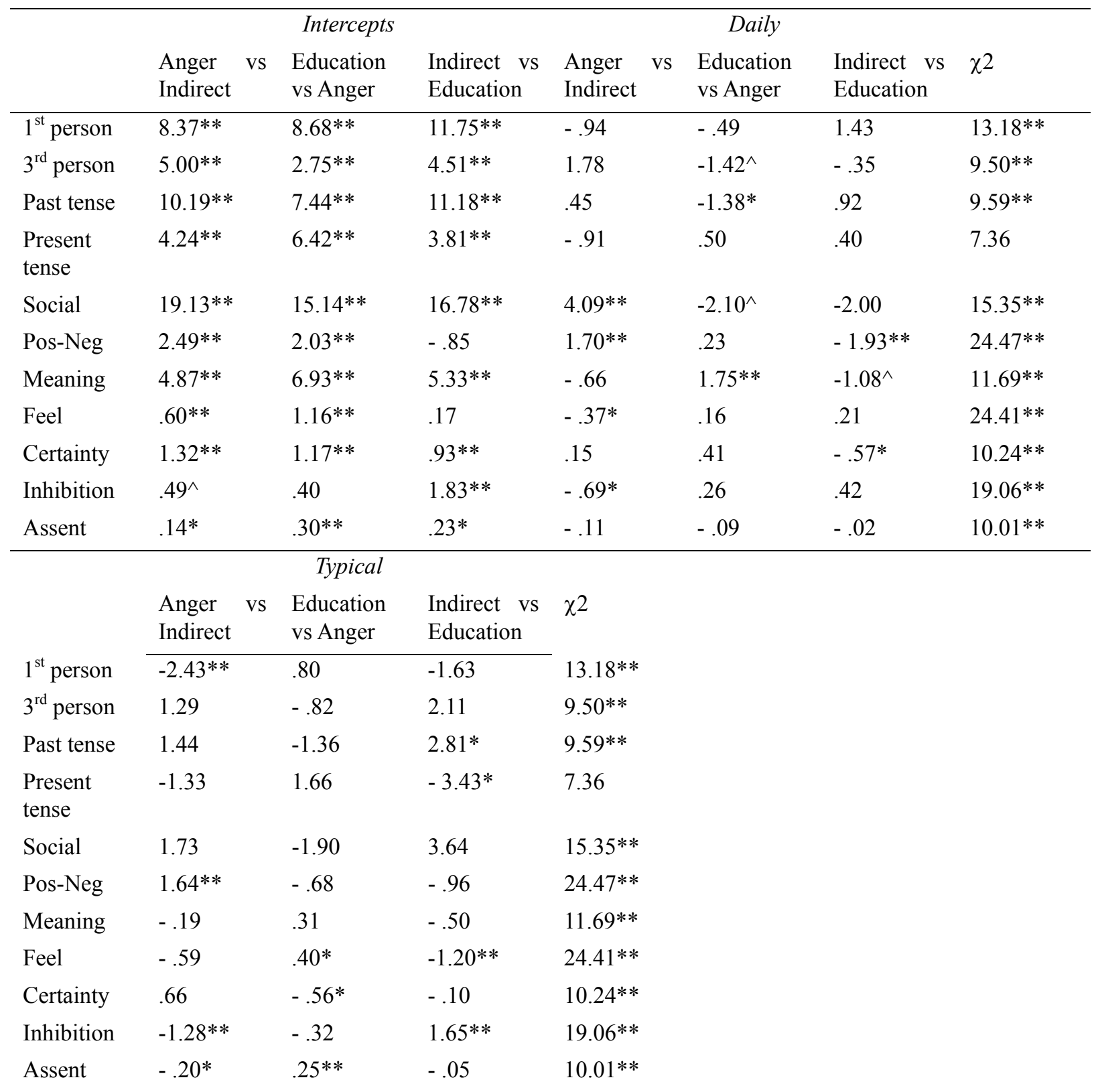

Note. Intercepts refer to the estimated percentage of total words used by an individual using the confrontation on day 1 and who typically uses that confrontation. The mean number of words/diary entry was $90.03, S D=60.8$, Minimum $=6$, Maximum $=362$.

$* p<.05, * * p<.01, \wedge p<.10$ 
Because LIWC (Pennebaker et al., 2007) includes anger in its negative emotion category, a new category for negative emotion was computed by removing the anger words so that it would not be confounded with angered confrontation. Otherwise, any relationship between angered confrontation and negative emotion could instead be due to both variables including a measure of anger. Thus, negative emotion referred to emotions such as sadness, anxiety, fear. Further, because well-being is associated with greater use of positive than negative emotion words (e.g., Pennebaker et al., 2003), a difference score was computed by subtracting the negative from positive emotion words. Thus, positive scores indicated the use of more positive than negative emotion words.

Results showed those who typically used angered confrontations also used fewer first-person singular pronouns (e.g., I, me), inhibition words (e.g., deny, abandon, ignore), and assent words (e.g., okay, yeah, yes) than those typically using indirect confrontations. Also, on days participants used angered confrontations, they used more social words (e.g., relationship, share), more third-person singular pronouns (e.g., she, he), fewer feel words (e.g., feeling, rough, heavy). Moreover, the use of positive relative to negative emotion words was higher when using angered confrontations (both typically, and daily) compared to when using indirect confrontations.

When comparing educational to angered confrontations, those typically using educational confrontations used more feel (e.g., rough) and assent (e.g., okay) words as well as fewer certainty (e.g., always) words than those typically using angered confrontations. Further, on days participants used educational confrontation, they reported fewer past tense words, marginally fewer social words (e.g., relationship) and third-person singular pronouns (e.g., she, he) and more meaning-making words than on days they used angered confrontation.

When comparing indirect to educational confrontations, those typically using indirect confrontation used more past tense and inhibition (e.g., ignore) words, fewer present tense and feel words (e.g., rough). On days participants used indirect confrontations their use of positive relative to negative emotion words was lower than on days they used educational confrontations. Moreover, on such days they reported marginally fewer meaning-making (e.g., cause, insight), and certainty (e.g., always) words than on days they used educational confrontation.

\section{Discussion}

The present study examined how different types of women's everyday confrontations against discrimination affect well-being over time. Consistent with expectations, confrontations had both positive and negative impacts on well-being, depending on the type of confrontation and when it was used. Initially, using angered confrontation predicted lower well-being than when using indirect confrontation. This is consistent with non-diary work examining confrontation at one point in time, showing confrontation is associated with decreased victim well-being (Bergman et al., 2002; Foster, 2009a; Wei et al., 2010). This may not be surprising given the social costs of confronting a perpetrator (e.g., Kaiser \& Miller, 2001); if confrontation elicits negativity from the perpetrator and observers, then the victim may suffer interpersonal repercussions again. Thus, it may be that the social costs of confrontation also have personal costs for the victims.

What is unique about this study however, is that it suggests the personal cost of angered confrontations is short-lived. Over time, using angered confrontation predicted increasing subjective well-being (mood, life satisfaction), and by month's end, predicted better well-being than indirect confrontation. Moreover, the linguistic data was consistent with the explicit measures of well-being. In particular, when using angered confrontations, use of positive relative to negative emotion words was higher than when using indirect confrontations, suggesting that angered confrontation was associated with more positive emotion. Further, use of feel words (e.g., feels, touch), which has been related to a focus on negative events (Guastella \& Dadds, 2006), was lower, suggesting that angered confrontation involved a lesser focus on negativity. Thus, despite being characterized as 'angry', both the explicit measures and linguistic markers of well-being suggest repeatedly using angered confrontation was associated with feeling good.

Interestingly however, typical users of angered confrontation used fewer meaning-making words than typical users of indirect confrontation. Meaning-making words when combined with the use of more positive than negative emotion words, are one of the linguistic hallmarks of well-being because they suggest the negative event has been cognitively processed and reappraised in a more positive way (e.g., Pennebaker, et al., 2003). As such, the benefits of expressing anger may not be through a cognitive processing of negative events. Instead, what was distinctive about using angered confrontation compared to using other confrontation types was that women used more social words (e.g., roommate, confided) and third-person singular pronouns (she, he), indicative of social connectedness (Burke \& Dollinger, 2005. For example, one participant used angered confrontation with a friend she is comfortable enough to be angry with: "I responded by saying, 'you're so racist' She was a friend so I was not scared to tell her." [Participant 32]. Another participant used anger when there 
were supportive people around:

I stopped the girl mid sentence and expressed to her my distain for her comments and how they were offensive to my father and mother, myself and all others who have married outside of their race and religion. After that, and my surrounding friends coming to my defense, I left. [Participant 27]

Thus, those typically using angered confrontation may have done so directly to supportive people, or when surrounded by supportive people. Future research will need to further explore how angered confrontations and social support may be related.

While angered confrontation was beneficial, continued use of indirect confrontations decreased psychological well-being; by the study's end, using indirect confrontations were associated with lower positive relations and mastery than when using angered confrontation. The detrimental effect of indirect versus angered confrontation is consistent with the theory that inhibiting one's emotions takes sustained effort and can ultimately take a toll on people's mental and physical resources, thereby decreasing well-being (e.g., Campbell \& Pennebaker, 2003; Frisina, Borod \& Lepore, 2004; King \& Miner, 2000). For example, when using indirect confrontations, participants described containing their emotions (e.g., "Because I generally don't like the person who said these racist comments I was somewhat angry, but I did not express my anger verbally. I basically just glared at him when he said it and got back to my homework." Participant 49). Word usage was also consistent with the notion that indirect confrontation involved emotional containment in that more inhibition words (e.g., abandon, cease, ignore) were used when using indirect than angered confrontation. Thus, compared to when using angered confrontation, use of indirect confrontation may involve suppressed emotion.

Continued use of indirect confrontation also predicted decreasing happiness over time. Word usage also supported this finding; compared to when using angered confrontation, fewer positive relative to negative emotion words were used when using indirect confrontation. Moreover, more feel words (e.g., rough) and more first-person singular pronouns (e.g., I, me) were used a greater focus on negativity and increased negative emotion such as grief and depression respectively, (Guastella \& Dadds, 2006; Rude, Gortner \& Pennebaker, 2004). Thus, indirect confrontation does not appear to be an effective route towards happiness and well-being.

Unexpectedly, educational confrontation showed the same detrimental pattern as indirect confrontation such that it was associated with decreasing psychological well-being. This may seem counter-intuitive given at first glance, educational confrontation appears to be a form of direct and assertive communication. However, educators note that when teaching about inequality, they often experience resistance, whereby students deny or legitimize injustice, ignore or silence the educator (e.g., Higginbotham, 1996, Meacham, 1995). Similarly, attempting to educate the perpetrator often involves repeated resistance from the perpetrator(s), perhaps in the form of justification of their behaviour, or hostility (Czopp \& Monteith, 2003; Czopp, Monteith \& Mark, 2006; Rasinski \& Czopp, 2010). Thus, if those trying to educate received resistance from perpetrators, this may have led participants to feel their confrontations had little impact, consistent with their declining sense of mastery.

Alternatively, educational confrontations may have been as detrimental as indirect confrontations because they may also involve emotional containment; women may have expressed why the perpetrator's behaviour was inappropriate, but were nevertheless attempting to be polite and calm, thereby containing negative emotions:

I told them, that it was inappropriate to make such comments, even if they don't mean to offend...Most of the things I really wanted to say, I kept to myself, because they are good friends of mine, but just make stupid comments when they are together in a group. [Participant 1]

Consistent with this description, those typically using educational confrontation used more feel (e.g., feel, rough) words than typical users of angered confrontation, suggesting they may be more immersed in the negative events they were describing (e.g., Guastella \& Dadds, 2006). As such, their use of positive relative to negative emotion words may not reflect "feeling good", but instead may be consistent with their attempts to be polite and calm. Moreover, although women used more meaning-making words, they also reported fewer past tense words than when using angered confrontation, suggesting these experiences may feel unresolved (Pasupathi, 2007). In addition, typical educational confronters also used fewer certainty words (e.g., always) compared to typical angered confronters, suggesting decreased feelings of power (Magee et al., 2010). If when using educational confrontation, women are trying to make meaning of their experience, but still feeling unresolved and uncertain, they may be ruminating. Thus, compared to angered confrontation, the combination of emotional suppression and rumination may contribute to why educational confrontations reduced well-being over time.

Notably, while use of indirect and educational confrontations showed the same detrimental pattern for well-being, and both suggest evidence of emotional suppression, the linguistic data may suggest a slight distinction between 
the two types of confrontations. When using indirect confrontations, women used fewer meaning-making words suggesting they were less likely to cognitively process the events compared to when using educational confrontations. Moreover, compared to typical users of educational confrontations, typical users of indirect confrontations used more past tense words, indicative of feeling resolved about an issue (Pasupathi, 2007). Thus, compared to when using educational confrontations, when using indirect confrontations there may be no attempt to cognitively process the events, and perhaps no intention to do so in the future. However, as suggested by the lower use of positive relative to negative words associated with indirect confrontation, such a strategy may not be effective.

In summary, angered confrontations may be better than indirect confrontations for well-being because, as the linguistic data suggests they involve emotional expression and social connectedness. Moreover, angered confrontations may be better than educational confrontations because the latter may involve emotional suppression, and rumination. Interestingly, angered confrontations were not detrimental to either form of well-being, but only enhanced measures of subjective well-being versus psychological well-being. It may be that expressing anger makes us feel good, but does not necessarily enhance the aspects of well-being that are indicative of a well-functioning individual (maintain positive relationships and being able to affect our environment). Neither educational nor indirect confrontation benefitted well being, but instead both were detrimental, and only for measures of psychological well-being, with the exception of happiness. Thus, holding back emotional expression may not only make us unhappy but impair communication necessary for positive relationships as well as one's sense of whether one can change one's environment (Greenberg, Rice, \& Elliott, 1993).

\subsection{Strengths, Weaknesses and Future Directions}

The current study purposely focused on undergraduate women given how much they experience discrimination at a young age (e.g., Statistics Canada, 2000, 2004). Teaching young women which confrontations can help or harm them may have important consequences for developing future patterns of behaviour. Nevertheless, research will also need to examine whether relationships between confrontations and well-being are similar for women with a wider range of life and work experience. For example, it is possible that using angered confrontation in a work environment may involve greater risks than in a university environment and as such, may negatively affect well-being.

Moreover, this study asked, "do types of confrontations of discrimination affect changes in well-being over time" as opposed to why these changes may occur. Indeed, the question of what may moderate or mediate these relationships remains. Although the present study found no individual differences in age and ethnicity, future research will need to examine other moderators and mediators that may account for the changes. For example, research suggests that how women define an action in terms of dimensions such as individual/collective and cost moderate the well-being effects (Foster, 2013). Future research will also examine the role of emotional expression and perpetrator resistance may play a role in how each confrontation affects well-being.

Finally, an argument could be made that changes in well-being were due to participants' increased attention to discrimination rather than the confrontations themselves. Indeed, sensitization effects, whereby the participant develops a heightened awareness of the problem, are a potential difficulty with any diary methodology (DeLongis et al., 1992). At the same time however, it is unclear whether sensitization effects would have occurred in the current data. First, DeLongis et al. (1992) argue that it is unclear whether such effects persist throughout the study, and may be a function of severity of the behavior being recorded. The current study showed that severity did not increase over time, thus, sensitization effects may be less of an issue in this data. This is consistent with past diary work that has shown perceived pervasiveness of discrimination did not increase over time, suggesting that attending to discrimination each day did not increase women's sensitivity to discrimination (Foster, 2009b). Moreover, the current study also showed no main effect of confrontation, suggesting that their use of particular confrontations did not increase or decrease during the study. As such, the methodology itself did not appear to affect which confrontations were preferred either. Finally, if changes in well-being were a function of attending to discrimination rather than confrontations themselves, it may be expected that well-being would change equally across the confrontations; this was not the case. Thus, while sensitization effects are limitation of diary methodology generally, it is unclear whether they affected the current data.

Despite limitations, this study contributes both theoretical and practical extensions to the literature. First, although work on collective action shows that confrontation can increase well-being, this study examined how the confrontations women use every day affect well-being. Further, by incorporating time, this study shows that 
confrontation can be both good and bad for women's well-being depending on the type and whether it is used continuously over time. Practically, it may be important to convey to women that while confronting discrimination may be initially difficult, continuing to do so may ultimately benefit personal well-being. In contrast, nice women may indeed finish last because being calm, polite or indirect in these confrontations may only serve to reduce such benefits.

\section{Acknowledgements}

This study was supported by the Social Sciences and Humanities Research Council of Canada [grant number 410-2005-0256)].

Portions of the data were presented at the meeting of the European Association of Social Psychology in Stockholm, Sweden (July, 2011).

\section{References}

Becker, J. C., Tausch, N., \& Wagner, U. (2011). Emotional consequences of collective action participation: Differentiating self-directed and outgroup-directed emotions. Personality and Social Psychology Bulletin, 37, 1587-1598. http://dx.doi.org/10.1177/0146167211414145

Bergman, M., Lanhout, R. D., Palmieri, P. A., Cortina, L. M., \& Fitzgerald, L. F. (2002). The (un) reasonableness of reporting: Antecedents and consequences of reporting sexual harassment. Journal of Applied Psychology, 87, 230-242. http://dx.doi.org/10.1037/0021-9010.87.2.230

Boals, A., \& Klein, K. (2005). Word use in emotional narratives about failed romantic relationships and subsequent mental health. Journal of Language and Social Psychology, 24, 252-268. http://dx.doi.org/10.1177/0261927X05278386

Bolger, N., Davis, A., \& Rafaeli, E. (2003). Diary methods: Capturing life as it is lived. Annual Review of Psychology, 54, 579-616. http://dx.doi.org/10.1146/annurev.psych.54.101601.145030

Branscombe, N. R., Schmitt, M. T., \& Harvey, R. D. (1999). Perceiving pervasive discrimination among African-Americans: Implications for group identification and well-being. Journal of Personality and Social Psychology, 77, 135-149. http://dx.doi.org/10.1037/0022-3514.77.1.135

Brinkman, B. G., \& Rickard, K. M. (2009). College students' descriptions of everyday gender prejudice. Sex Roles, 61, 461-475. http://dx.doi.org/10.1007/s11199-009-9643-3

Burke, P. A., \& Dollinger, S. J. (2005). A picture's worth a thousand words: Language use in autophotographic essay. Personality and Social Psychology Bulletin, 31, 536-548. http://dx.doi.org/10.1177/0146167204271714

Campbell, R. S., \& Pennebaker, J. W. (2003). The secret life of pronouns: Flexibility in writing style and physical health. Psychological Science, 14, 60-65. http://dx.doi.org/10.1111/1467-9280.01419

Cocking, C., \& Drury, J. (2004). Generalization of efficacy as a function of collective action and intergroup relations: Involvement in an anti-roads struggle. Journal of Applied Social Psychology, 34, 417-444. http://dx.doi.org/10.1111/j.1559-1816.2004.tb02555.x

Cook, T. D., \& Campbell, D. T. (1979). Quasi-Experimentation: Design and Analysis for Field Settings. Rand McNally, Chicago, Illinois.

Contrada, R. J., Ashmore, R. D., Gary, M. L., Coups, E., Egeth, J. D., Sewell, A. et al. (2001). Measures of ethnic related stress: Psychometric properties, ethnic group differences, an associations with well-being. $\begin{array}{lllll}\text { Journal of Applied } & \text { Social } & \text { Psychology, } & 31, & \text { 1775-1820. }\end{array}$ http://dx.doi.org/10.1111/j.1559-1816.2001.tb00205.x

Corbin, J., \& Strauss, A. (2008). Basics of qualitative research (3rd ed.). Los Angeles, CA: Sage.

Cresswell, J. W. (2008). Qualitative inquiry and research design: Choosing among five approaches. (2nd ed.). Thousand Oaks, CA: Sage.

Crosby, F. J. (1984). The denial of personal discrimination. American Behavioral Scientist, 27, 371-386. http://dx.doi.org/10.1177/000276484027003008

Czopp, A., \& Monteith, M. J. (2003). Confronting prejudice (literally): Reactions to confrontations of racial and gender bias. Personality and Social Psychology Bulletin, 29, 532-544. http://dx.doi.org/10.1177/0146167202250923

Czopp, A., Monteith, M. J., \& Mark, A. Y. (2006). Standing up for a change: Reducing bias through interpersonal 


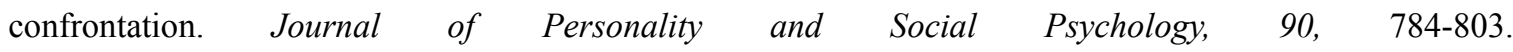
http://dx.doi.org/10.1037/0022-3514.90.5.784

DeLongis, A., Hemphill, K. J., \& Lehman, D. R. (1992). A structured diary methodology for the study of daily events. In F. B. Bryant et al. (Eds.), Methodological issues in applied social psychology: Social psychological applications to social issues (vol. 2, pp. 83-109). New York, NY, US: Plenum Press. http://dx.doi.org/10.1007/978-1-4899-2308-0_5

Diener, E. (1984). Subjective well-being. Psychological Bulletin, 95, 542-575. http://dx.doi.org/10.1037/0033-2909.95.3.542

Drury, J., Cocking, C., Beale, J., Hanson, C., \& Rapley, F. (2005). The phenomenology of empowerment in collective action. British Journal of Social Psychology, 44, 309-328. http://dx.doi.org/10.1348/014466604X18523

Drury, J., \& Reicher, S. (1999). The intergroup dynamics of collective empowerment: Substantiating the social identity model. Group Processes and Intergroup Relations, 2, 381-402. http://dx.doi.org/10.1177/1368430299024005

Ellemers, N., \& Barreto, M. (2009). Collective action in modern times: How modern expressions of prejudice $\begin{array}{llllll}\text { prevent collective action. Journal of Social Issues, 65, 749-768. } & \text {. }\end{array}$ http://dx.doi.org/10.1111/j.1540-4560.2009.01621.x

Foa, E., \& Kozak, M. (1986). Emotion processing of fear: Exposure to corrective information. Psychological Bulletin, 99, 20-35. http://dx.doi.org/10.1037/0033-2909.99.1.20

Foster, M. D. (2000). Positive and negative responses to personal discrimination: Does coping make a difference? Journal of Social Psychology, 140, 93-106. http://dx.doi.org/10.1080/00224540009600448

Foster, M. D. (2001). The motivational quality of global attributions in hypothetical and experienced situations of gender discrimination. Psychology of Women Quarterly, 25, 242-253. http://dx.doi.org/10.1111/1471-6402.00025

Foster, M. D. (2009a). The dynamic nature of coping with gender discrimination: Appraisals, strategies and well-being over time. Sex Roles, 60, 694-707. http://dx.doi.org/10.1007/s11199-008-9568-2

Foster, M. D. (2009b). Perceiving pervasive discrimination over time: Implications for coping. Psychology of Women Quarterly, 33, 172-182. http://dx.doi.org/10.1111/j.1471-6402.2009.01487.x

Foster, M. D. (2013). The interaction between taking action against discrimination and perceived pervasiveness on well-being. Manuscript submitted for publication.

Foster, M. D., \& Dion, K. L. (2003). Dispositional hardiness and women's well-being relating to gender discrimination: The role of minimization. Psychology of Women Quarterly, 27, 197-208. http://dx.doi.org/10.1111/1471-6402.00099

Foster, M. D., Jackson, C. L., Hartmann, R., \& Woulfe, S. (2004). Minimizing the pervasiveness of women's personal experiences of gender discrimination. Psychology of Women Quarterly, 28, 224-232. http://dx.doi.org/10.1111/j.1471-6402.2004.00139.x

Frisina, P. G., Borod, J. C., \& Lepore, S. J. (2004). A meta-analysis of the effects of written emotional disclosure on the health outcomes of clinical populations. The Journal of Nervous and Mental Disease, 192, 629-634. http://dx.doi.org/10.1097/01.nmd.0000138317.30764.63

Garcia, D. M., Reser, A. H., Amo, R. B., Redersdorff, S., \& Branscombe, N. R. (2005). Perceivers' responses to in-group and out-group members who blame a negative outcome on discrimination. Personality and Social Psychology Bulletin, 31, 769-780. http://dx.doi.org/10.1177/0146167204271584

Gortner, E. M., \& Pennebaker, J. W. (2003). The archival anatomy of a disaster: Media coverage and community-wide health effects of the Texas A\&M bonfire tragedy. Journal of Social and Clinical Psychology, 22, 580-603. http://dx.doi.org/10.1521/jscp.22.5.580.22923

Greenberg, L. S., Rice, L. N., \& Elliott, R. (1993). Facilitating emotional change. New York, NY: Guilford.

Guastella, A. J., \& Dadds, M. R. (2006). Cognitive-behavioral models of emotional writing: A validation study. Cognitive Therapy and Research, 30, 397-414. http://dx.doi.org/10.1007/s10608-006-9045-6

Haslam, S. A., Jetten, J., Postmes, T., \& Haslam, C. (2009). Social identity, health and well-being: An emerging $\begin{array}{llllll}\text { agenda for applied } & \text { psychology. Applied }\end{array}$ 
http://dx.doi.org/10.1111/j.1464-0597.2008.00379.x

Hellawell, S. J., \& Brewin, C. R. (2004). A comparison of flashbacks and ordinary autobio- graphical memories of trauma: Content and language. Behaviour Research and Therapy, 42, 1-12. http://dx.doi.org/10.1016/S0005-7967(03)00088-3

Higginbotham, E. (1996). Getting all students to listen: Analyzing and coping with student resistance. American Behavioural Scientist, 40, 203-211. http://dx.doi.org/10.1177/0002764296040002011

Huffaker, D. A., Swaab, R., \& Diermeier, D. (2011). The language of coalition formation in online multiparty negotiations. Journal of Language and Social Psychology, 30, 66-81. http://dx.doi.org/10.1177/0261927X10387102

Hyers, L. L. (2007). Resisting prejudice every day: Exploring women's assertive responses to anti-black racism, anti-Semitism, heterosexism, and sexism. Sex Roles, 56, 1-12. http://dx.doi.org/10.1007/s11199-006-9142-8

Hyers, L. L. (2010). Alternatives to silence in face-to-face encounters with heterosexism: Activism on the interpersonal front. Journal of Homosexuality, 57, 539-565. http://dx.doi.org/10.1080/00918361003608749

Jetten, J., Branscombe, N. R., Schmitt, M. T., \& Spears, R. (2001). Rebels with a cause: Group identification as a response to perceived discrimination from the mainstream. Personality and Social Psychology, 27, 1204-1213. http://dx.doi.org/10.1177/0146167201279012

John, O. P., \& Srivastava, S. (1999). The Big five trait taxonomy: History, measurement and theoretical perspectives. In L. A. Pervin, \& O. P. John (Eds.), Handbook of personality, theory and research (pp. 102-138). New York: Guilford.

Kaiser, C. R., \& Miller, C. T. (2001). Stop complaining! The social costs of making attributions to discrimination. Personality and Social Psychology Bulletin, 27, 254-263. http://dx.doi.org/10.1177/0146167201272010

Kaiser, C. R., \& Miller, C. T. (2003). Derogating the victim: The interpersonal consequences of blaming events on discrimination. Group Processes and Intergroup Relations, 6, 227-237. http://dx.doi.org/10.1177/13684302030063001

Kanner, A. D., Coyne, J. C. Schaefer, C., \& Lazarus, R. S. (1981). Comparison of two modes of stress measurement: Daily hassles and uplifts versus major life events. Journal of Behavioral Medicine, 4, 1-39. http://dx.doi.org/10.1007/BF00844845

King, L. A., \& Miner, K. N. (2000). Writing about the perceived benefits of traumatic events: Implications for physical health. Personality \& Social Psychology Bulletin, 26, 220-230. http://dx.doi.org/10.1177/0146167200264008

Klonoff, E. A., Landrine, H., \& Campbell, R. (2000). Sexist discrimination may account for well-known gender differences in psychiatric symptoms. Psychology of Women Quarterly, 24, 93-99. http://dx.doi.org/10.1111/j.1471-6402.2000.tb01025.x

LaFrance, M., \& Harris, J. (2004). Gender and verbal and nonverbal communication. In M. A. Paludi (Ed.), Praeger guide to the psychology of gender (pp. 133-154). Westport, CT, US: Praegar Publishers.

Lazarus, R. S. (1993). Coping theory and research: Past, present and future. Psychosomatic Medicine, 55, 234-247.

Lazarus, R. S., \& Folkman, S. (1984). Stress, appraisal and coping. New York, NY: Springer.

Magee, J. C., Milliken, F. J., \& Lurie, A. R. (2010). Power differences in the construal of a crisis: The immediate aftermath of September 11, 2001. Personality and Social Psychology Bulletin, 36, 354-370. http://dx.doi.org/10.1177/0146167209360418

Matheson, K., \& Anisman, H. (2009). Anger and shame elicited by discrimination: Moderating role of coping on action endorsements and salivary cortisol. European Journal of Social Psychology, 39, 163-185. http://dx.doi.org/10.1002/ejsp.522

McCrae, R. R., \& Costa, P. T., Jr. (1987). Validation of a five-factor model of personality across instruments and observers. Journal of Personality and Social Psychology, 52, 81-90. http://dx.doi.org/10.1037/0022-3514.52.1.81

Meacham, J. (1995). Conflict in multicultural classes: Too much heat or too little? Liberal Education, 81, 24-29.

Moradi, B., \& Subich, L. M. (2002). Perceived sexist events and feminist identity development attitudes: Links to women's psychological distress. The Counseling Psychologist, 30, 44-65. 
http://dx.doi.org/10.1177/0011000002301003

Outten, H. R., Schmitt, M. T., Garcia, D. M., \& Branscombe, N. R. (2009). Coping options: Missing links between minority group identification and psychological well-being. Applied Psychology: An International Review, 58, 146-170. http://dx.doi.org/10.1111/j.1464-0597.2008.00386.x

Pasupathi, M. (2007). Telling and the remembered self: Linguistic differences in memories for previously disclosed and previously undisclosed events. Memory, 15, 258-270. http://dx.doi.org/10.1080/09658210701256456

Pennebaker, J. W., Chung, C. K., Ireland, M., Gonzales, A., \& Booth, R. J. (2007). The development and psychometric properties of LIWC2007 [LIWC manual]. Austin, TX: LIWC.net.

Pennebaker, J. W., \& Chung, C. K. (2007). Expressive writing, emotional upheavals and health. In H. S. Friedman, \& R. C. Silver (Eds.), Foundations of health psychology (pp. 263-284). New York, NY, US: Oxford University Press.

Pennebaker, J. W., Mehl, M. R., \& Niederhoffer, K. G. (2003). Psychological aspects of natural language use: Our words, our selves. Annual Review of Psychology, 54, 547-577. http://dx.doi.org/10.1146/annurev.psych.54.101601.145041

Pillemer, D. B., Desrochers, A. B., \& Ebanks, C. M. (1998). Remembering the past in the present: Verb tense shifts in autobiographical memory narratives. In C. P. Thompson, D. J. Herrmann, D. Bruce, J. D. Read, D. G. Payne, \& M. P. Toglia (Eds.), Autobiographical memory: Theoretical and applied perspectives (pp. 145-162). New York: Lawrence Erlbaum.

Pressman, S. D., \& Cohen, S. (2007). Use of social words in autobiographies and longevity. Psychosomatic Medicine, 69, 262-269. http://dx.doi.org/10.1097/PSY.0b013e31803cb919

Radloff, L. S. (1977). The CES-D scale: A self-report depression scale for research in the general population. Applied Psychological Measurement, 1, 385-401. http://dx.doi.org/10.1177/014662167700100306

Rasinski, H. M., \& Czopp, A. M. (2010). The effect of target status on witnesses' reactions to confrontation of bias. Basic and Applied Psychology, 32, 8-16. http://dx.doi.org/10.1080/01973530903539754

Revicki, D. A., Turner, R., Brown, R., \& Martindale, J. J. (1992). Batelle quality of life scale. Quality of Life Research, 1, 257-266. http://dx.doi.org/10.1007/BF00435635

Rude, S., Gortner, E. M., \& Pennebaker, J. (2004). Language use of depressed and depression-vulnerable college students. Cognition \& Emotion, 18, 1121-1133. http://dx.doi.org/10.1080/02699930441000030

Ryff, C., \& Keyes, C. L. M. (1995). The structure of psychological well-being revisited. Journal of Personality and Social Psychology, 69, 719-727. http://dx.doi.org/10.1037/0022-3514.69.4.719

Schmitt, M. T., Branscombe, N. R., Kobrynowicz, D., \& Owen, S. (2002). Perceiving discrimination against one's gender group has different implications for well-being in women and men. Personality and Social Psychology Bulletin, 28, 197-210. http://dx.doi.org/10.1177/0146167202282006

Schmitt, M. T., Branscombe, N. R., \& Postmes, T. (2003). Women's emotional responses to the pervasiveness of gender discrimination. European Journal of Social Psychology, 33, 1-12. http://dx.doi.org/10.1002/ejsp.131

Shelton, J. N., Richeson, J. A., Salvatore, J., \& Hill, D. M. (2006). Silence is not golden: The Intrapersonal consequences of not confronting prejudice. In S. Levin, \& C. van Laar (Eds.), Stigma and group inequality. Mahwah, NJ: Lawrence Erlbaum Associates, Inc.

Sloan, D. M. (2005). It's all about me: Self-focused attention and depressed mood. Cognitive Therapy and Research, 29, 279-288. http://dx.doi.org/10.1007/s10608-005-0511-1

Singer, J. D., \& Willett, J. B. (2003). Applied longitudinal data analysis: Modeling change and event occurrence. New York, NY: Oxford University Press. http://dx.doi.org/10.1093/acprof:oso/9780195152968.001.0001

Snijders, T., \& Bosker, R. (1999). Multilevel analysis: An introduction to basic and advanced multilevel modeling. London:Sage.

Statistics C. (2000). Women in Canada 2000: A gender-based statistical report. Statistics Canada Catalogue no. 89-503-XPE.

Statistics C. (2004). Family violence in Canada: A statistical profile 2004. Retrieved September 15, 2008, from http://www5.statcan.gc.ca/bsolc/olc-cel/olc-cel?catno=85-224-X\&chropg=1)=eng 
Stroebe, K., Barreto, M., \& Ellemers, N. (2010). When searching hurts: The role of information search in reactions to gender discrimination. Sex Roles, 62, 60-76. http://dx.doi.org/10.1007/s11199-009-9700-y

Swim, J. K., Hyers, L. L., Cohen, L. L., \& Ferguson, M. J. (2001). Everyday sexism: Evidence for its incidence, nature and psychological impact from three daily diary studies. Journal of Social Issues, 57, 31-53. http://dx.doi.org/10.1111/0022-4537.00200

Swim, J. K., Hyers, L. L., Cohen, L. L., Fitzgerald, D. F., \& Bylsma, W. H. (2003). African American college students' experiences with everyday racism: Characteristics of and responses to these incidents. Journal of Black Psychology, 29, 38-67. http://dx.doi.org/10.1177/0095798402239228

Taylor, D. M., Wright, S. C., Moghaddam, F. M., \& Lalonde, R. N. (1990). The personal/group discrimination discrepancy: Perceiving my group, but not myself, to be a target for discrimination. Personality and Social Psychology Bulletin, 16, 254-263. http://dx.doi.org/10.1177/0146167290162006

Tausczik, Y. R., \& Pennebaker, J. W. (2010). The psychological meaning of words: LIWC and computerized text analysis methods. Journal of Language and Social Psychology, 29, 24-54. http://dx.doi.org/10.1177/0261927X09351676

Townsend, S., Major, B., Gangi, C., \& Mendes, W. B. (2011). From 'in the air' to 'under the skin': Cortisol responses to social identity threat. Personality and Social Psychology Bulletin, 37, 151-164. http://dx.doi.org/10.1177/0146167210392384

Van Zomeren, M., Drury, J., \& Van der Staaij, M. (2012). Experimental evidence for the empowering consequences of collective action. Manuscript submitted for publication.

Watson, D., \& Clark, L. A. (1994). The PANAS-X: The Manual for the positive and negative affect scale-Expanded form. Unpublished manuscript. University of Iowa, Iowa City, IA.

Wei, M., Alvarez, A. N., Ku, T-Y., Russell, D., Bonett, D. G., et al. (2010). Development and validation of a coping with discrimination scale: Factor structure, reliability and validity. Journal of Counseling Psychology, 57, 328-344. http://dx.doi.org/10.1037/a0019969

Wright, S. C. (2001). Restricted intergroup boundaries: Tokenism, ambiguity, and the tolerance of injustice. In J. T. Jost, \& B. Major (Eds.), The psychology of legitimacy: Emerging perspectives on ideology, justice, and intergroup relations (pp. 223-254). New York, NY: Cambridge University Press.

Zucker, A. N., \& Landry, L. J. (2007). Embodied discrimination: The relation of sexism and distress to women's drinking and smoking behaviors. Sex Roles, 56, 193-203. http://dx.doi.org/10.1007/s11199-006-9163-3

\section{Notes}

Note 1. Inaction was not used in the analyses because it may not have been a meaningful category. Despite instructions to describe, not the discrimination experience itself, but how they responded to it, many participants described only their experience. Because such responses could not be classified as an observable behaviour, these descriptions were given the code, inaction. However, it was unclear whether these participants were choosing not to respond, or whether they misunderstood or were inattentive to the instructions. For example, had participants been attending to instructions, those choosing to be inactive may have written, "I did nothing". As such, the inaction category may not be as meaningful given it may have been confounded with an inattention to instructions.

Note 2. The extent to which confrontations may change over time was tested, however there were no significant effects suggesting that participants did not systematical increase/decrease their use of particular confrontations in one direction over time.

Note 3. This variable had a significant main effect only on positive relations and mastery, and did not significantly interact with time (see Table 2). As such, the variable was included as a main effect only in those models.

\section{Copyrights}

Copyright for this article is retained by the author(s), with first publication rights granted to the journal.

This is an open-access article distributed under the terms and conditions of the Creative Commons Attribution license (http://creativecommons.org/licenses/by/3.0/). 